\title{
Galantamine versus donepezil in Chinese patients with Alzheimer's disease: results from a randomized, double-blind study
}

This article was published in the following Dove Press journal:

Neuropsychiatric Disease and Treatment

3 December 2012

Number of times this article has been viewed

\section{Zhenxin Zhang' \\ Lu Yu \\ Maren Gaudig ${ }^{3}$ \\ Barbara Schäuble ${ }^{4}$ \\ Ute Richarz ${ }^{5}$ \\ 'Department of Neurology of Peking Union Medical College Hospital, ${ }^{2}$ Xi'an Janssen Pharmaceutical Ltd, Beijing, China; ${ }^{3}$ Health Economics and Reimbursement, Janssen-Cilag EMEA, Neuss, Germany; ${ }^{4}$ Formerly of EMEA Medical Affairs, Janssen-Cilag EMEA, Neuss, Germany; ${ }^{5}$ Global Medical Affairs, Janssen Global Services LLC, Janssen-Cilag AG, Baar, Switzerland}

Correspondence: Ute Richarz Global Medical Affairs Lead, Johnson and Johnson, Janssen-Cilag $\mathrm{GmbH}$, Sihlbruggstrasse III, 6340 Baar, Switzerland

Tel +4l4 I767342I

Email uricharl@its.jnj.com
Background: Acetylcholinesterase inhibitors are considered standard of care for Alzheimer's disease in many countries. Galantamine is an acetylcholinesterase inhibitor that may also act via allosteric modulation of nicotinic acetylcholine receptors. Therefore, it may provide benefits compared with other acetylcholinesterase inhibitors. The present study compared galantamine $(\mathrm{n}=116)$ with donepezil $(\mathrm{n}=117)$ in a double-blind trial at nine hospitals in China.

Methods: After washout of any previous acetylcholinesterase inhibitors, subjects with mild to moderate Alzheimer's disease received galantamine or donepezil for 16 weeks.

Results: Alzheimer's Disease Assessment Scale - cognitive subscale (ADAS-cog/11) scores improved significantly from baseline in both treatment arms, with a significant difference in favor of galantamine on the "language" functional area $(P=0.035)$. Significantly more galantamine-treated patients responded to treatment (defined as a reduction in ADAS-cog/11 score of $>4,>7$, or $>10$ points; all $P<0.05)$, and had an ADAS-cog/11 score $<20$ at end point $(P=0.015)$. Both treatments were well tolerated, although fewer galantamine-treated patients experienced gastrointestinal adverse events compared with donepezil (30\% versus $48 \%$ ).

Conclusion: Cognitive function improved significantly in subjects with mild to moderate Alzheimer's disease treated with galantamine or donepezil, and both treatments were generally well tolerated. Significant benefits for galantamine over donepezil were observed for language and response to treatment.

Keywords: Chinese, donepezil, galantamine, randomized controlled trial, Alzheimer's disease

\section{Introduction}

Alzheimer's disease is a progressive neurodegenerative disorder with a mean duration of around 8.5 years between onset of clinical symptoms and death. Brain regions that are associated with higher mental functions, particularly the neocortex and hippocampus, are those most affected by the characteristic pathology of Alzheimer's disease. Subsequent discoveries of reduced choline uptake, acetylcholine release, and loss of cholinergic perikarya from the nucleus basalis of Meynert confirmed a substantial presynaptic cholinergic deficit. Thus, it was proposed that degeneration of cholinergic neurons in the basal forebrain, and the associated loss of cholinergic neurotransmission in the cerebral cortex and other areas, contribute significantly to the deterioration in cognitive function seen in patients with Alzheimer's disease. As a result, acetylcholinesterase inhibitors were developed for the symptomatic treatment of patients with mild to moderate Alzheimer's disease, and are considered standard of care in many countries worldwide. ${ }^{1-4}$ 
Galantamine is an acetylcholinesterase inhibitor that, in addition to acetylcholinesterase inhibition, may also act through allosteric modulation of nicotinic acetylcholine receptors. ${ }^{5}$ Therefore, it may provide additional benefits compared with donepezil or rivastigmine.

Several attempts have been made to differentiate between acetylcholinesterase inhibitors on the basis of safety and efficacy. A meta-analysis by the Cochrane Collaboration found that all acetylcholinesterase inhibitors produced improvements in cognitive function when compared with placebo, with an average change (improvement) in the 11-point Alzheimer's Disease Assessment Scale - cognitive subscale (ADAS-cog/11) of -2.7 points ( $95 \%$ confidence interval -3.0 to -2.3$){ }^{6}$ In one study of galantamine versus placebo, the improvement over placebo was 3.09 points. ${ }^{7}$ The safety profile of donepezil and galantamine did not differ significantly in the Cochrane analysis. ${ }^{6}$

Two rater-blinded, randomized comparative trials of donepezil and galantamine have been conducted. In a 52-week study in the UK comparing galantamine and donepezil, 182 subjects receiving galantamine maintained Mini-Mental State Examination scores at baseline levels throughout the study, compared with a significant deterioration in those receiving donepezil $(P<0.0005$ versus baseline $) .{ }^{8}$ Activities of daily living and behavioral outcomes were similar between the two treatment arms, although more caregivers of subjects receiving galantamine reported reductions in burden compared with donepezil. In a 12-week multinational study in which 120 subjects were treated with donepezil or galantamine, ADAS-cog/11 and Disability Assessment in Dementia scores were significantly improved in the donepezil arm compared with galantamine at week $12 .{ }^{9}$ Furthermore, fewer donepezil-treated subjects reported gastrointestinal adverse events.

The objective of the present double-blind study was to compare cognitive outcomes in patients with mild to moderate Alzheimer's disease receiving either galantamine or donepezil, based on the hypothesis that galantamine would be noninferior to donepezil.

\section{Materials and methods \\ Study design}

GAL-CH-100 was a randomized, double-blind, parallel-group, 16-week study conducted at nine hospitals in China. Subjects first completed a screening period of up to 14 days. Those previously receiving acetylcholinesterase inhibitors then entered a 4-week, single-blind placebo washout period, while those not previously receiving acetylcholinesterase inhibitors proceeded directly to the double-blind phase.
At double-blind baseline, subjects were randomly allocated (1:1) to galantamine or donepezil. Galantamine was dosed at $8 \mathrm{mg} /$ day for 4 weeks, followed by $16 \mathrm{mg}$ /day for 4 weeks. In weeks 9-12, subjects received flexible-dose galantamine (6-24 mg/day) at the investigator's discretion, followed by a fixed galantamine dose of 16 or $24 \mathrm{mg}$ /day in weeks $13-16$, depending on tolerability of the dose they received in weeks 9-12. Donepezil was dosed at $5 \mathrm{mg} /$ day for 8 weeks, followed by flexible dosing (5-10 mg/day) in weeks 9-12. In weeks 13-16, subjects received a fixed donepezil dose of 5 or $10 \mathrm{mg}$ /day depending on dose in weeks $9-12$ and tolerability.

\section{Patients}

Eligible subjects were men or women aged 40-90 years with a diagnosis of probable Alzheimer's disease, according to the criteria of the National Institute of Neurological and Communicative Disorders and Stroke and the Alzheimer's Disease and Related Disorders Association, and a MiniMental State Examination score of 10-24. Subjects were also required to have a permanent caregiver during the study. Those with neurodegenerative diseases, encephalosis, or vascular dementia were excluded. Additional exclusion criteria included epilepsy, depression, schizophrenia, active peptic ulcers, significant liver, kidney, lung, metabolic, or endocrine anomalies, significant urinary obstructions, and cardiovascular disease. Written informed consent was obtained from subjects, or their legal representatives, and their caregivers.

\section{End points}

The primary efficacy outcome measure was the ADAS-cog/11. Prespecified secondary analyses included six functional areas of the ADAS-cog/11 (operation, memory, orientation, visual space, language, attention), and the response to treatment, defined as a reduction in ADAS-cog/ 11 score of $>0,>4,>7$, or $>10$ points. In addition, efficacy was assessed using the Alzheimer's Disease Cooperative Study Activities of Daily Living Inventory and the Neuropsychiatric Inventory. Safety was assessed in terms of adverse events, laboratory tests, physical examination, and vital signs.

\section{Statistical analysis}

The sample size for the study was based on an expected between-group difference of 2.47 , with a standard deviation of 7.1. With $\alpha=0.05$ and $80 \%$ power of a test, 103 subjects are required for each treatment arm. With an estimated dropout rate of $20 \%$, a sample size of 258 was required.

Efficacy was assessed in the full analysis set, which was defined as all subjects who were randomized and received 
at least one dose of double-blind study drug, and had at least one post-baseline primary end point assessment. Safety was assessed in the safety population, defined as all subjects who were randomized and received at least one dose of doubleblind study drug.

The primary end point was the change on ADAS-cog/11 at end point versus baseline at week 16 , and was analyzed by analysis of covariance with treatment as a factor and site as a covariate. Secondary end points were analyzed using analysis of covariance, adjusted for study center, to evaluate the differences of efficacy between galantamine and donepezil. The analysis of response to treatment was analyzed using the Cochran-Mantel-Haenszel test, adjusted for study center. No missing data were imputed.

\section{Results}

\section{Subjects}

In total, 233 subjects were randomly allocated to treatment (galantamine, $\mathrm{n}=116$; donepezil, $\mathrm{n}=117$ ), which was lower than the predetermined sample size for the study. The 16-week study was completed by 198 subjects ( $85 \%$, Figure 1$)$. The full analysis set included 218 subjects (galantamine, $\mathrm{n}=110$; donepezil, $\mathrm{n}=108)$, of whom $198(91 \%)$ completed the study. Baseline characteristics were similar between the two study arms (Table 1). The majority of patients in the study were aged 65-85 years, with no significant difference in mean age, duration of cognitive impairment, or duration of Alzheimer's disease between the treatment arms (Table 1). At the end of treatment, 80 galantamine-treated (69\%) and 71 donepezil-treated (61\%) subjects were receiving the highest
Table I Baseline characteristics (FAS)

\begin{tabular}{|c|c|c|c|}
\hline & $\begin{array}{l}\text { Galantamine } \\
(n=110)\end{array}$ & $\begin{array}{l}\text { Donepezil } \\
(\mathrm{n}=108)\end{array}$ & $P$-value \\
\hline Age (mean $\pm S D$ ), years & $73.3 \pm 8.5$ & $74.0 \pm 8.4$ & 0.609 \\
\hline Distribution, n (\%) & & & 0.556 \\
\hline$<65$ years & $15(14)$ & $20(19)$ & \\
\hline $65-85$ years & $91(83)$ & $83(77)$ & \\
\hline$>85$ years & $4(4)$ & $5(5)$ & \\
\hline Sex, n (\%) & & & 0.591 \\
\hline Male & $54(49)$ & $49(45)$ & \\
\hline Female & $56(5 \mathrm{I})$ & $59(55)$ & \\
\hline $\begin{array}{l}\text { Duration of cognitive } \\
\text { impairment (mean } \pm S D \text { ), } \\
\text { years }\end{array}$ & $3.0 \pm 2.2$ & $3.3 \pm 2.6$ & 0.276 \\
\hline $\begin{array}{l}\text { Duration of } A D \\
(\text { mean } \pm S D) \text {, years }\end{array}$ & $0.7 \pm 1.3$ & $0.7 \pm 1.1$ & 0.930 \\
\hline MMSE score & $18.8 \pm 3.8$ & $17.9 \pm 4.1$ & 0.089 \\
\hline ADAS-cog/II & $22.5 \pm 9.3$ & $23.3 \pm 9.6$ & 0.542 \\
\hline $\begin{array}{l}\text { Prior use of cholinergic } \\
\text { drugs, } n(\%)^{\mathrm{a}}\end{array}$ & $23(21)$ & $30(28)$ & 0.122 \\
\hline
\end{tabular}

Note: ${ }^{\text {aAll }}$ patients receiving cholinergic drugs at screening underwent a 4-week washout period.

Abbreviations: AD, Alzheimer's disease; ADAS-cog/lI, Alzheimer's Disease Assessment Scale - cognitive subscale; FAS, full analysis set; MMSE, Mini-Mental State Examination; SD, standard deviation.

maintenance dose (galantamine $24 \mathrm{mg} /$ day or donepezil $10 \mathrm{mg} /$ day).

\section{Efficacy}

At week 16, mean ADAS-cog/11 scores improved (decreased) significantly from baseline in both treatment arms (Figure 2). While there was no significant difference between the galantamine and donepezil arms overall, improvement was numerically greater with galantamine than with done-

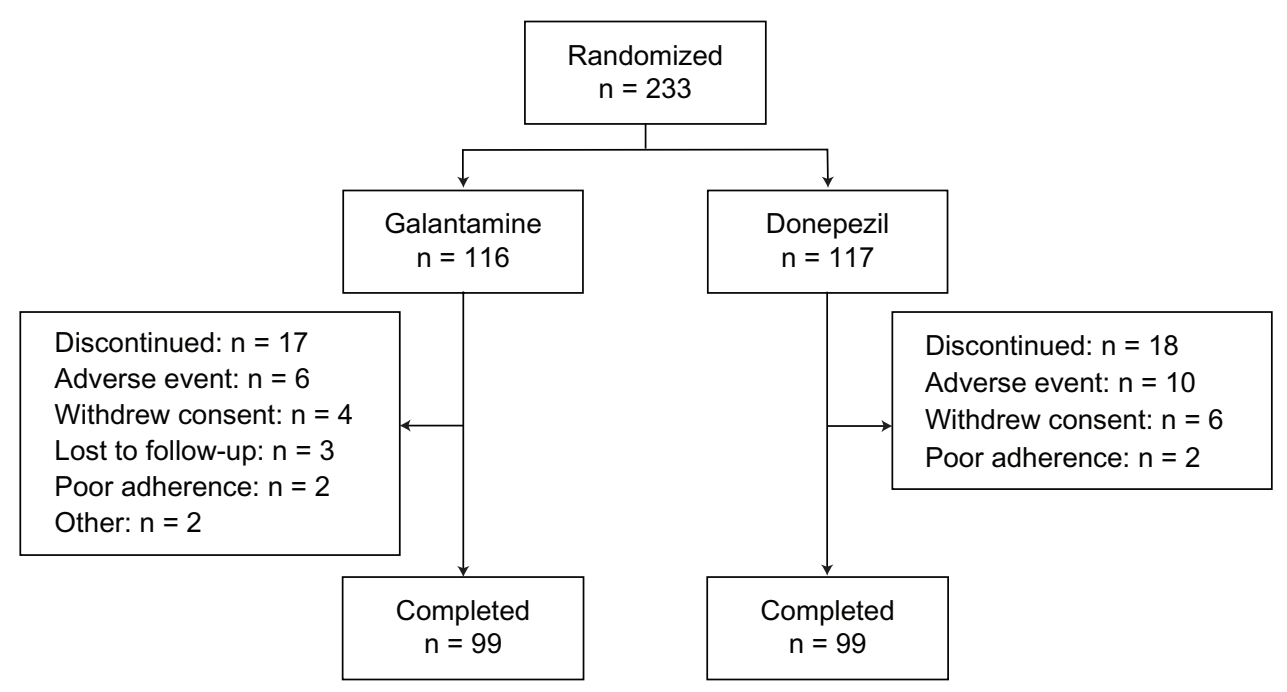

Figure I Patient disposition. 


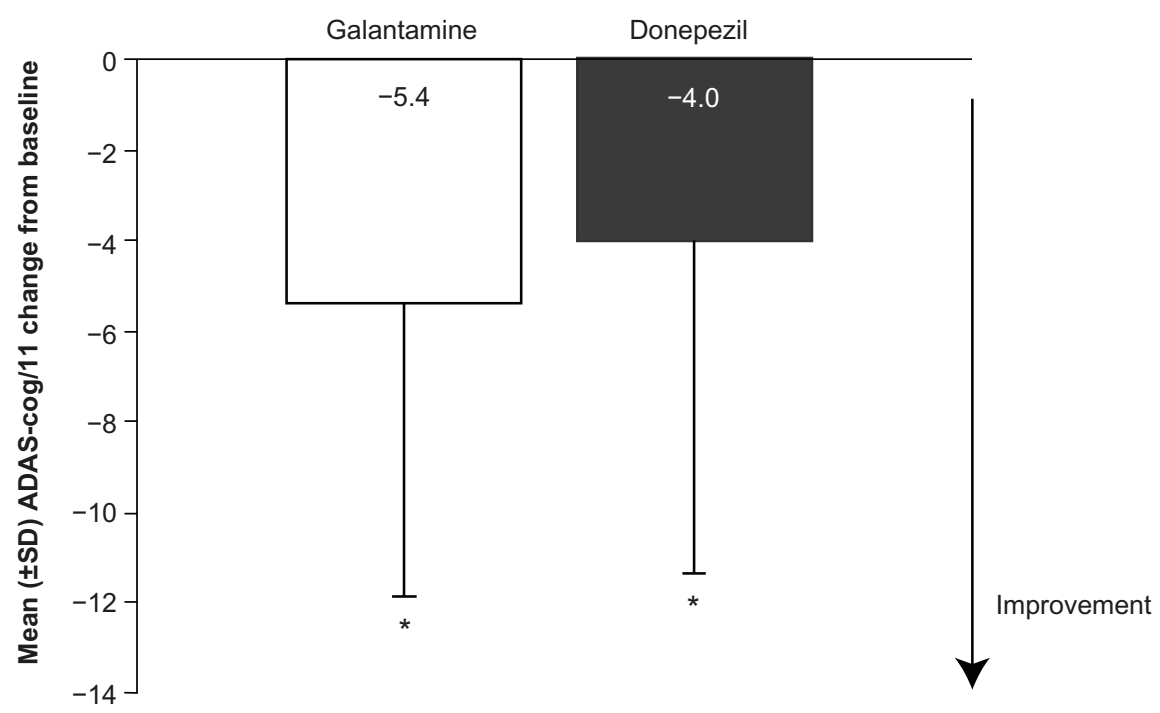

Figure 2 Mean change from baseline in Alzheimer's Disease Assessment Scale - cognitive subscale (ADAS-cog/I I) score. Note: ${ }^{*} P<0.05$ vs baseline.

pezil. Furthermore, galantamine was superior to donepezil for improving the "language" functional area of the ADAS-cog/11 ( $P=0.035$, Table 2). No significant differences between galantamine and donepezil were observed for the other ADAS-cog/11 functional areas.

The proportion of subjects who maintained ADAS-cog/11 at or above baseline levels was $82 \%$ with galantamine $(n=90)$ and $78 \%$ with donepezil $(n=84)$. Response to treatment, as determined by reductions in ADAS-cog/11 score of $>4,>7$,

Table 2 Mean scores on the six ADAS-cog/I I functional areas at baseline and week 16

\begin{tabular}{|c|c|c|c|}
\hline & $\begin{array}{l}\text { Galantamine } \\
(n=I \mid 0)\end{array}$ & $\begin{array}{l}\text { Donepezil } \\
(\mathrm{n}=\mathrm{I08})\end{array}$ & $P$-value \\
\hline \multicolumn{4}{|c|}{ Operation } \\
\hline Baseline & $2.8 \pm 2.2$ & $2.8 \pm 2.0$ & \\
\hline Week 16 & $1.9 \pm 2.1$ & $2.0 \pm 2.0$ & 0.883 \\
\hline \multicolumn{4}{|l|}{ Memory } \\
\hline Baseline & $11.0 \pm 4.0$ & $\mathrm{II} .4 \pm 4.2$ & \\
\hline Week 16 & $8.5 \pm 4.2$ & $9.6 \pm 4.6$ & 0.430 \\
\hline \multicolumn{4}{|c|}{ Orientation } \\
\hline Baseline & $2.9 \pm 1.7$ & $3.4 \pm 2.0$ & \\
\hline Week 16 & $2.4 \pm 2.0$ & $3.0 \pm 2.2$ & 0.449 \\
\hline \multicolumn{4}{|c|}{ Visual space } \\
\hline Baseline & $1.3 \pm 0.9$ & $1.3 \pm 1.1$ & \\
\hline Week 16 & $2.4 \pm 2.0$ & $3.0 \pm 2.2$ & 0.420 \\
\hline \multicolumn{4}{|l|}{ Language } \\
\hline Baseline & $2.8 \pm 2.9$ & $2.8 \pm 3.0$ & \\
\hline Week 16 & $1.8 \pm 2.5$ & $2.3 \pm 2.9$ & 0.035 \\
\hline \multicolumn{4}{|c|}{ Attention } \\
\hline Baseline & $2.8 \pm 2.2$ & $2.9 \pm 2.2$ & \\
\hline Week 16 & $2.0 \pm 2.2$ & $2.2 \pm 2.2$ & 0.579 \\
\hline
\end{tabular}

Abbreviation: ADAS-cog/II, Alzheimer's Disease Assessment Scale - cognitive subscale. and $>10$ points, was achieved by significantly more subjects receiving galantamine (Figure 3 ). Significantly more subjects receiving galantamine had an ADAS- $\operatorname{cog} / 11$ score $<20$ at end point compared with donepezil $(76 \%[\mathrm{n}=78]$ versus $58 \%[\mathrm{n}=60] ; P=0.015$ ).

Mean ( \pm standard deviation) improvements from baseline in Alzheimer's Disease Cooperative Study Activities of Daily Living Inventory score at week 16 were similar with galantamine and donepezil $(2.0 \pm 12.1$ versus $3.1 \pm 10.1)$, as were mean improvements in Neuropsychiatric Inventory score $(0.4 \pm 8.3$ versus $0.3 \pm 8.0)$.

\section{Safety}

Of the 233 subjects, 51 (44\%) in the galantamine arm and $54(47 \%)$ in the donepezil arm reported at least one adverse event, of which most were transient and mild to moderate in severity. The most common adverse events in both treatment arms were nausea, vomiting, and dizziness (Table 3), although fewer galantamine-treated patients experienced adverse gastrointestinal events compared with donepezil ( $30 \%$ versus $48 \%$ ). Adverse events considered by the investigator to be possibly, probably, or almost certainly related to treatment were reported by $28 \%$ and $40 \%$ of patients receiving galantamine or donepezil, respectively.

Discontinuations because of adverse events occurred in six patients $(5 \%)$ in the galantamine arm and 10 patients $(8.4 \%)$ in the donepezil arm. Serious adverse events considered to be possibly related to treatment occurred in one patient in each treatment arm (purpura and thrombocytopenia with galantamine; abnormal liver function tests with 


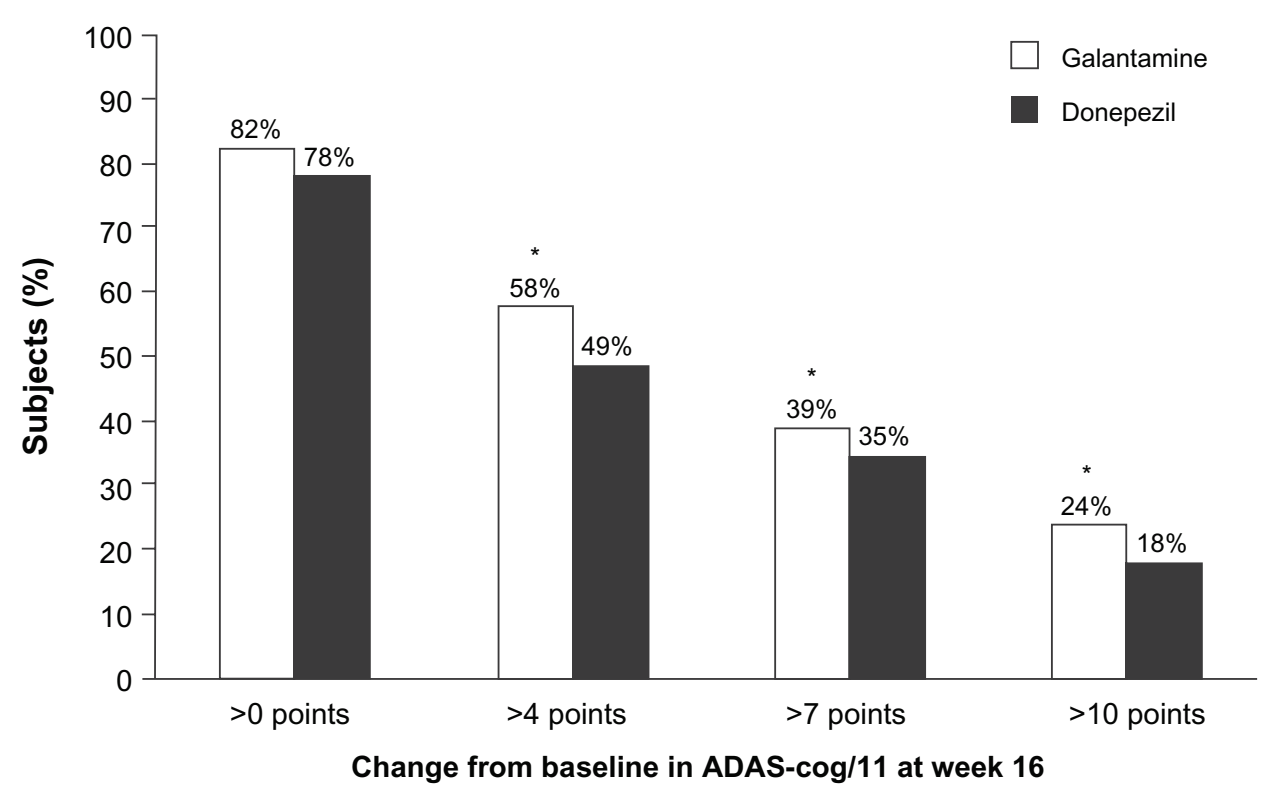

Figure 3 Percentage of patients with an improvement from baseline of $>0,>4,>7$, and $>10$ points on the Alzheimer's Disease Assessment Scale - cognitive subscale (ADAS-cog/II).

Note: ${ }^{*} P<0.05$ vs donepezil.

donepezil). No deaths were reported during the study. No clinically significant differences between treatment groups were reported for laboratory tests, vital signs, or physical examination.

\section{Discussion}

Few comparative studies of galantamine and donepezil have been conducted previously, with only two rater-blinded trials comparing the two drugs over 16 and 52 weeks. ${ }^{8,9}$ While the shorter of these (a 16-week trial) yielded more positive results for donepezil, the longer trial (12 months) showed superiority of galantamine over donepezil with regard to cognition. The present 16-week multicenter, double-blind trial demonstrated that improvements in cognitive function (ADAS-cog/11), daily

Table 3 Adverse events occurring in $\geq 3 \%$ of subjects in either treatment arm

\begin{tabular}{lll}
\hline Adverse event, $\mathbf{n}(\%)$ & $\begin{array}{l}\text { Galantamine } \\
\text { (n = I I6) }\end{array}$ & $\begin{array}{l}\text { Donepezil } \\
\text { (n= I I7) }\end{array}$ \\
\hline Any adverse event & 5 I (44) & $54(47)$ \\
Nausea & $15(I 3)$ & $25(22)$ \\
Vomiting & $7(6)$ & II (9) \\
Dizziness & $8(7)$ & $9(8)$ \\
Anorexia & $3(3)$ & $7(6)$ \\
Diarrhea & $4(3)$ & $4(3)$ \\
Sinus bradycardia & $2(2)$ & $4(3)$ \\
Belching & I (I) & $3(3)$ \\
Premature contraction & $3(3)$ & 0 \\
Urinary tract infection & $3(3)$ & I (I) \\
\hline
\end{tabular}

living capabilities (Alzheimer's Disease Cooperative Study Activities of Daily Living Inventory), and neuropsychiatric symptoms (Neuropsychiatric Inventory) in Chinese patients with Alzheimer's disease are broadly similar with galantamine (16-24 mg/day) and donepezil (5-10 mg/day). However, the overall level of response in terms of ADAS-cog/11 score (ie, improvement of $>4,>7$, or $>10$ points) was significantly better with galantamine than with donepezil. Furthermore, improvement in the ADAS-cog/11 functional area of language ability, a composite of the ADAS-cog/11 items "spoken language ability," "word-finding difficulty", and "comprehension in spontaneous speech", was significantly greater with galantamine than with donepezil. Previous data on language performance in patients with Alzheimer's disease receiving galantamine or donepezil are limited. A 24-week study in 1467 patients with moderate to severe Alzheimer's disease showed no benefit of donepezil $10 \mathrm{mg} /$ day on language assessed using the Severe Impairment Battery - Language scale. ${ }^{10}$ However, significant improvements in language were seen when the donepezil dose was increased to $23 \mathrm{mg}$ /day. In a secondary analysis of a 4-month, placebo-controlled trial of galantamine in 130 community-dwelling patients with mild to moderate Alzheimer's disease, significantly more patients receiving galantamine experienced a reduction in verbal repetition compared with those receiving placebo (58\% versus $24 \%, P<0.01) .{ }^{11}$

In the present study, as in placebo-controlled studies, ${ }^{7,12-15}$ galantamine was well tolerated. Furthermore, unlike the 
previous 16-week comparative study of galantamine and donepezil, ${ }^{9}$ the present study showed a lower overall adverse event rate for galantamine and a lower frequency of gastrointestinal adverse events. The slight differences in outcomes of the different comparative studies may be attributable to treatment duration, study design, and patient variability.

Overall, the results of this study in Chinese patients are consistent with those from randomized, double-blind, placebo-controlled trials of galantamine, which were performed mostly in Caucasian patients. ${ }^{7,12-15}$ These studies show that treatment significantly improves cognitive function, daily functioning, and behavior. Open-label data from Chinese individuals are available from a small $(n=32)$ 2-year study in which galantamine was effective in slowing cognitive decline compared with historical controls. ${ }^{16}$

The main strengths of the present study are its doubleblind, active-comparator design, and its reporting of key outcomes, subgroup analyses, and adverse event profiles. The main weakness of the study is its sample size, which was four patients per treatment arm smaller than determined in the sample size calculation. However, the dropout rate in the study $(15 \%)$ was lower than that used in the sample size calculation (20\%). Additional limitations of the study are the lack of data imputation (although the rate of discontinuation was similar in the two treatment arms), the inclusion (albeit with a washout period) of patients who had previously received cholinesterase inhibitors, the relatively short follow-up, and the lack of data on APP, PSEN1, PSEN2, and $A p o E$ genotypes among the participants.

In conclusion, while improvements in cognition were generally similar in the galantamine and donepezil arms, response to treatment (reductions in ADAS$\operatorname{cog} / 11$ score $>4,>7$, and $>10$ points), language ability (in terms of the "language" functional area of the ADAS$\operatorname{cog} / 11)$, and the percentage of patients with low cognitive impairment (ADAS-cog/11 score < 20) were significantly greater with galantamine.

\section{Disclosure}

The GAL-CH-100 study was sponsored by Xian-Janssen Pharmaceutical Ltd, Beijing, China. Editorial support with drafting and completion of the manuscript was provided by Daniel Booth (Bioscript Medical Ltd, London, UK) and funded by Janssen-Cilag EMEA. Some data from this study have previously been published in Chinese (Hong X, et al. Zhonghua Shen Jing Ge Za Zhi. 2006;39:379-382). LY is an employee of Xi'an Janssen Pharmaceutical Ltd, Beijing,
China. MG is an employee of Janssen-Cilag EMEA, Neuss, Germany. BS is a former employee of Janssen-Cilag EMEA, Neuss, Germany. UR is an employee of Janssen-Cilag AG, Baar, Switzerland.

\section{References}

1. National Institute for Health and Clinical Excellence. Donepezil, Galantamine, Rivastigmine (Review) and Memantine for the Treatment of Alzheimer's Disease (Amended). London, UK: National Institute for Health and Clinical Excellence; 2007.

2. Deutsche Gesellschaft für Psychiatrie Psychotherapie und Nervenheilkunde, Deutsche Gesellschaft für Neurologie. S3-Leitlinie "Demenzen". [German Association for Psychiatry and Psychotherapy; German Society of Neurology. S3 guideline "Dementia"]. 2009. Available from: http://www.dgn.org/images/stories/dgn/leitlinien/ 11_demenz/11-demenz-kurz-170210.pdf. Accessed January 15, 2011.

3. Socialstyrelsen. Nationella riktlinjer för vård och omsorg vid demenssjukdom 2010 - stöd för styrning och ledning. [The National Board of Health and Welfare (Sweden). National guidelines for care in dementia 2010 - support for governance and management]. Västerås: Edita Västra Aros; 2010.

4. American Psychiatric Association. Practice Guideline for the Treatment of Patients with Alzheimer's Disease and Other Dementias, 2nd ed. Arlington, VA: American Psychiatric Publishing Inc; 2007.

5. Samochocki M, Hoffle A, Fehrenbacher A, et al. Galantamine is an allosterically potentiating ligand of neuronal nicotinic but not of muscarinic acetylcholine receptors. J Pharmacol Exp Ther. 2003;305: 1024-1036.

6. Birks J. Cholinesterase inhibitors for Alzheimer's disease. Cochrane Database Syst Rev. 2006;1:CD005593.

7. Raskind MA, Peskind ER, Wessel T, et al. Galantamine in AD: A 6-month randomized, placebo-controlled trial with a 6-month extension. The Galantamine USA-1 Study Group. Neurology. 2000;54:2261-2268.

8. Wilcock G, Howe I, Coles H, et al. A long-term comparison of galantamine and donepezil in the treatment of Alzheimer's disease. Drugs Aging. 2003;20:777-789.

9. Jones RW, Soininen H, Hager K, et al. A multinational, randomised, 12-week study comparing the effects of donepezil and galantamine in patients with mild to moderate Alzheimer's disease. Int J Geriatr Psychiatry. 2004;19:58-67.

10. Ferris SH, Schmitt FA, Saxton J, et al. Analyzing the impact of $23 \mathrm{mg} /$ day donepezil on language dysfunction in moderate to severe Alzheimer's disease. Alzheimers Res Ther. 2011;3:22.

11. Rockwood K, Fay S, Jarrett P, et al. Effect of galantamine on verbal repetition in AD: a secondary analysis of the VISTA trial. Neurology. 2007;68:1116-1121.

12. Rockwood K, Mintzer J, Truyen L, et al. Effects of a flexible galantamine dose in Alzheimer's disease: a randomised, controlled trial. J Neurol Neurosurg Psychiatry. 2001;71:589-595.

13. Tariot PN, Solomon PR, Morris JC, et al. A 5-month, randomized, placebo-controlled trial of galantamine in AD. The Galantamine USA-10 Study Group. Neurology. 2000;54:2269-2276.

14. Wilcock GK, Lilienfeld S, Gaens E. Efficacy and safety of galantamine in patients with mild to moderate Alzheimer's disease: multicentre randomised controlled trial. Galantamine International-1 Study Group. BMJ. 2000;321:1445-1449.

15. Brodaty H, Corey-Bloom J, Potocnik FC, et al. Galantamine prolonged-release formulation in the treatment of mild to moderate Alzheimer's disease. Dement Geriatr Cogn Disord. 2005;20:120-132.

16. Chu LW, Yik PY, Mok W, et al. A 2-year open-label study of galantamine therapy in Chinese Alzheimer's disease patients in Hong Kong. Int $J$ Clin Pract. 2007;61:403-410. 
Neuropsychiatric Disease and Treatment

Dovepress

\section{Publish your work in this journal}

Neuropsychiatric Disease and Treatment is an international, peerreviewed journal of clinical therapeutics and pharmacology focusing on concise rapid reporting of clinical or pre-clinical studies on a range of neuropsychiatric and neurological disorders. This journa is indexed on PubMed Central, the 'PsycINFO' database and CAS.

The manuscript management system is completely online and includes a very quick and fair peer-review system, which is all easy to use. Visit http://www.dovepress.com/testimonials.php to read real quotes from published authors.

Submit your manuscript here: http://www.dovepress.com/neuropsychiatric-disease-and-treatment-journal 